\title{
Comparison of Shoot through Technique for Series Z-Source Inverter \\ ${ }^{* 1}$ Rahul V Adle, ${ }^{2}$ Mohan M Renge \\ ${ }^{1}$ G. H. Raisoni Institute of Engineering and Technology, Nagpur \\ ${ }^{2}$ Shri Ramdeobaba College of Engineering and Management, Nagpur Email: rahuladle@yahoo.co.in, rengemm@rknec.edu
}

Received: 20th November 2019, Accepted: 31st January 2020, Published: 29th February 2020

\begin{abstract}
Z-source inverter (ZSI) can boost the de link voltage of an inverter using shoot through state. Shoot through can be achieved in all three phase i.e. phase $r$, phase $y$, phase $b$. In shoot through state, upper three and lower three switches of the same phase leg of the inverter are turn ON. There are different ways of shoot through by making ON two switches of the phase $r$ or $y$ or $b$ or $r y$ or $y b$ or $b a$ or $r y b$. ZSI can enter in to shoot through state with boost operation depending upon modulating index. In this paper different shoot through technique for series Z-source inverter (SZSI) are presented. In shoot through state inductors becomes in charge position while capacitors are in discharge position and in non shoot through it is vice versa. Simulation results validate the performance of SZSI.
\end{abstract}

\section{Keywords}

Series Z-source Inverter, Shoot Through, Modulation Index.

\section{Introduction}

The sinusoidal pulse width modulation (SPWM) technique is most efficient technology used for voltage source inverter (VSI) fed drive system, FACTS devices and renewable energy converter. In solar PV system, there is a requirement of $\mathrm{dc}$ voltage boosting. Therefore two converters are needed, one for boosting dc voltage and other to convert dc to ac. To overcome the above limitations, single stage power conversion ability namely Z-source inverter (ZSI) was invented [1]. ZSI can boost the dc link voltage of an inverter using shoot through state. In shoot through state, upper three and lower three switches of the same phase leg of inverter are turn on intentionally. ZSI proposed in [1] combines both conversions. ZSI can provide wide range of PV voltage variation [2]. As a result, system price and the devices are reduced with improved reliability. As described in [3] voltage equation for ZSI is

$V r m s=0.612 \times M \times B \times V d c$

$V d c=$ Dc voltage,

$M=$ Modulation index,

$B=$ Boost factor.

The boost factor is

$$
B=\frac{1}{1-2 D}
$$

$D=T_{0} / T$

Where, $T_{o}=$ shoot through time interval and $T$ is the total time interval of cycle. In shoot through, there is employment of straight line signal which is equal to or greater than three phases for controlling the shoot through duty ratio. For producing the larger voltage boost, $M$ must be lowered. Which further increases the total harmonics distortion (THD) value and finally the ac output voltage of inverter will be degraded [4] [5].

As compared with ZSI, SZSI can lower the size and cost of capacitors with higher power density. SZSI shown in Fig. 1 [6] [7] have more benefits as compared to the conventional ZSI such as reduced voltage, less inrush current [8]. In series ZSI, the inverter bridge is in series with power source shows the reduced voltage across capacitors. Duration of energy flow in SPWM controlled SZSI [7] is maximum as compared to the conventional ZSI. Therefore, power rating of source is reduced due to the use of SZSI. 


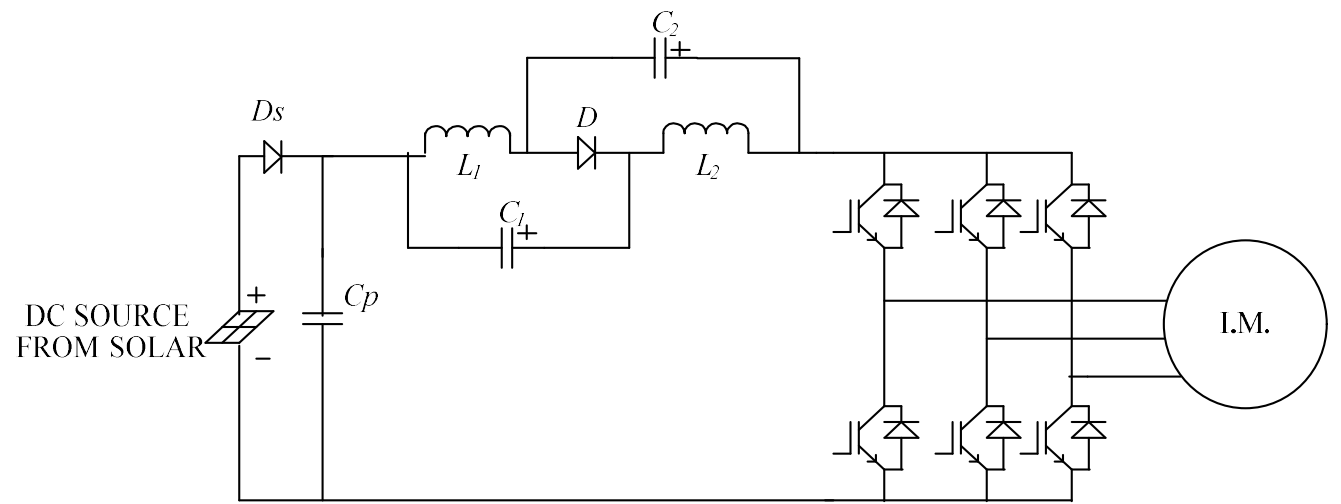

Fig.1: SZSI Fed an Induction Motor with Solar PV

\section{Materials and Methods}

The Shoot Through Technique:

\section{Conventional / Traditional Shoot Through Technique}

The shoot through (ST) state is forbidden in VSI. By controlling ST ratio, the de voltage is boosted and required ac output can be gained. Three phase voltage source inverter has six switches, using six switches there are eight switching combinations. In two states out of eight states, the entire upper three or lower three switches are ON. Shoot through is realized in these two states. For achieving this in the traditional control scheme, four control signals are used as shown in Fig. 2, $V_{r}, V_{y}, V_{b}$ are the three phase voltages. $V_{t}$ is shoot through control signal and by varying its value, $D$ is changed which increases the dc bus voltage. The magnitude of $V_{t}$ line signal is always more than the peak value of $V_{r}, V_{y}$ and $V_{b} . V_{t 1}$ is for above reference magnitude and $V_{t 2}$ is for below reference magnitude shown in Fig. 2 [7].

For traditional scheme $D$ is

$D=\frac{V_{c m}{ }^{*} V_{t}}{V_{c m}}$

where $V_{c m}$ is magnitude of triangular signal. The $V_{c}$ in traditional control scheme is given by

$$
V_{c}=\frac{(1-M)}{(2 M-1)} V_{d c}
$$

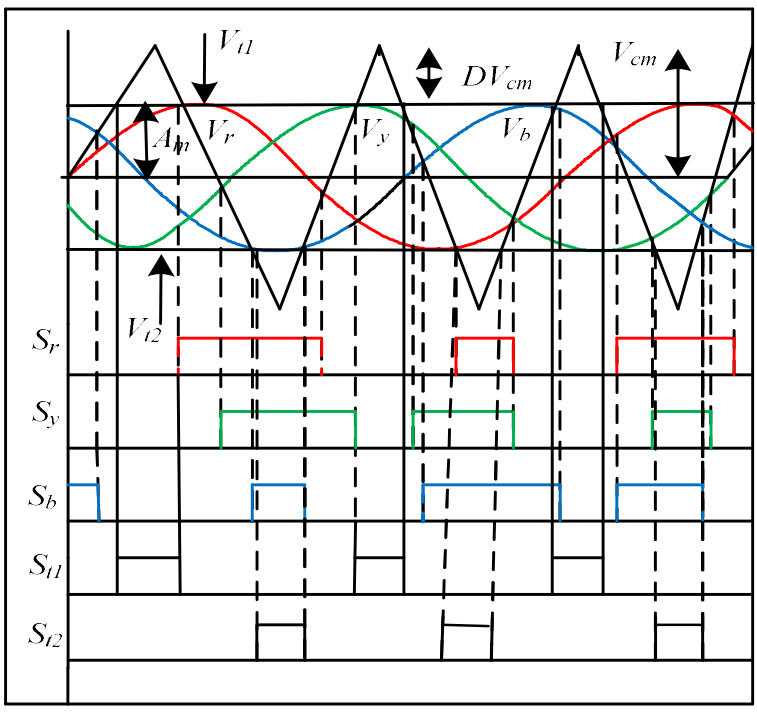

Fig. 2: Modulation Control Scheme 


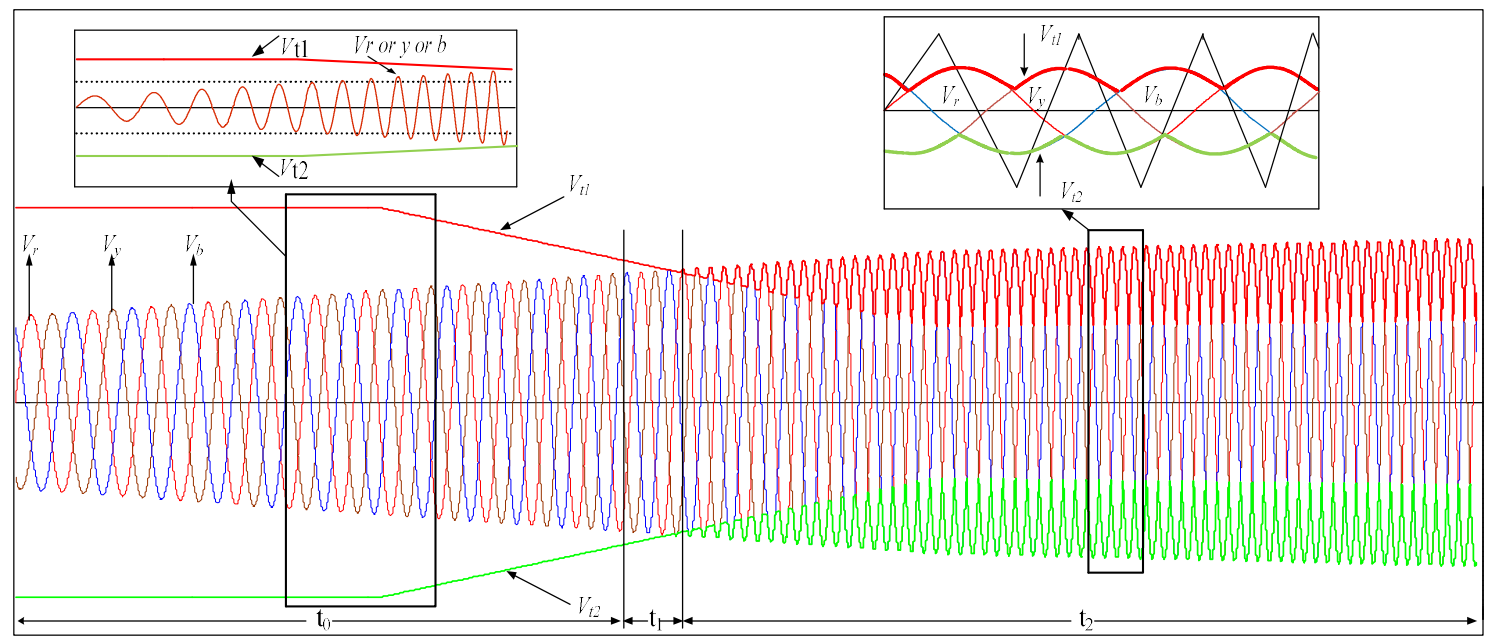

Fig. 3: Modified Modulation Control Scheme

\section{Improved/ Modified Shoot Through Technique with Soft Start}

An improved modulation strategy with modified shoot through envelop technique is used (Fig. 3). In modified control strategy, modulating signals used are $V_{r}, V_{y}, V_{b}, V_{t 1}$ and $V_{t 2}$, shown in Fig. 3. Where $V_{r}, V_{y}, V_{b}$ are sinusoidal control signals. $V_{t 1}$ and $V_{t 2}$ are the shoot through envelops signal for positive and negative magnitude respectively. When $V_{t 1}$ modulating signal is minimum than triangular signal and $V_{t 2}$ modulating signal is maximum than triangular signal, then inverter is in shoot through state. In improved control strategy, shoot through ratio changes with respect to time. The boosting ratio changes to $(1-0.5 M)$. Therefore, boosting of dc link voltage has been increased in modified strategy as compared to traditional control strategy. The modified control strategy has reduced the voltage stress on capacitor voltage and dc link. The modified control strategy provides scope for improvement in the modulating index with respect to traditional control scheme; therefore THD in output voltage reduces [8].

The capacitor voltage for modified control strategy (Fig. 3) is given by

$$
V_{C}=\left(\left(\frac{1}{\sqrt{3 M^{2}-1}} \ln \left|\frac{\sqrt{1.732 M-1}+(0.268) \sqrt{1.732 M+1}}{\sqrt{1.732 M-1}-(0.268) \sqrt{1.732 M+1}}\right|\right)-\frac{\pi}{6}\right) \times V_{P V}
$$

\section{Soft Starting of Modulation Strategy}

Three phase sinusoidal control signals $\left(V_{r}\right.$ or $V_{y}$ or $\left.V_{b}\right)$ with soft start are shown in Fig. 3, having shoot through signals $V_{t 1}$ and $V_{t 2}$. Voltage and frequency ratio is constant at start and modulating index has increased the output of an inverter with frequency.

Duration ( $\left.\mathbf{t}_{\mathbf{0}}\right)$ : in this time period $\left(\mathrm{t}_{0}\right)$, no shoot through occurs. Modulating index increases output voltage of an inverter with constant $\mathrm{V} / \mathrm{f}$ ratio shown in Fig. 3.

Duration ( $\left.t_{1}\right)$ : in this time period $\left(t_{1}\right)$, traditional shoot through starts (duration $t_{1}$ ) and maintains voltage and frequency ratio constant with an increase in output voltage of an inverter. Shoot through ratio increases dc link voltage as well as output voltage of inverter shown in Fig. 3.

Duration ( $\left.\mathbf{t}_{2}\right)$ : At the beginning of time period, $t_{2}$ modified shoot through envelop starts. This modified shoot through technique increases output voltage of an inverter with required value shown in Fig. 3.

\section{Results and Discussion}

Simulation has been carried out for validating the performance of SZSI based 3 phase induction motor drive system. Source is solar photovoltaic. The simulation parameters are given above: $L_{1}=L_{2}=3.0 \mathrm{mH}, C_{1}=C_{2}=470$ $\mu \mathrm{F}$; Load: three phase induction motor, $80 \mathrm{~V}, 2.3 \mathrm{~A}, 50 \mathrm{~Hz}, 2880 \mathrm{rpm}, 180 \mathrm{~W}$. SPWM technique along with modified control strategy is used for $M=0.9, f_{s}=10 \mathrm{kHz}$ and $V_{P V}=69.5 \mathrm{~V}$.

Solar PV voltage is $69.0 \mathrm{~V}$ (Fig. 4(a)). DC bus voltage is $155 \mathrm{~V}$ (Fig. 4 (b)). Capacitor voltage is $43.0 \mathrm{~V}$ (Fig. 4 (c)). 

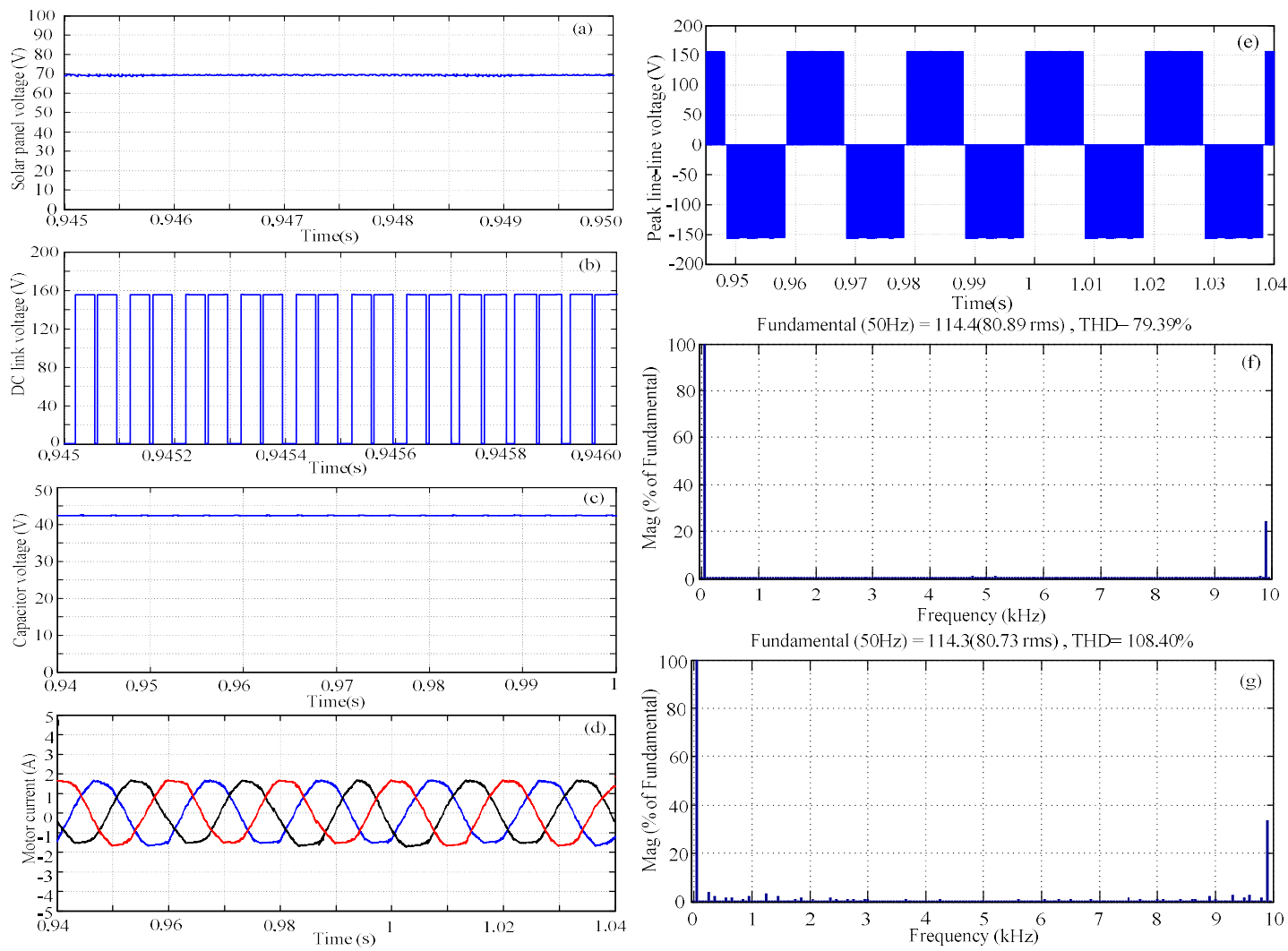

Fig. 4: Simulation Results of SZSI Fed Induction Motor, (a) Solar DC Voltage, (b) DC Bus Voltage, (c) Capacitor Voltage, (d) Motor current (e) Line Voltage, (f) FFT for Modified Control Strategy, (g) FFT for Traditional Control Strategy.

The output voltage for inverter is $155 \mathrm{~V}$ (Fig. 4 (e)). The motor current is 1.05 A (Fig. 4 (d)). In case of traditional control strategy for making the line voltage as per improved control strategy, ST is increased. In simulink, modulation index is 0.7 for traditional control strategy and THD in line voltage is $108.40 \%$ (Fig. $4(\mathrm{~g})$ ). While in modified strategy THD is $79.39 \%$ (Fig. 4 (f).

\section{Conclusion}

A proposed modified modulation strategy provides a scope for improvement in the modulation index as compared to traditional modulation strategy; hence, THD in output voltage is reduced as compared to the traditional control strategy. Also due to proposed modulation technique value of solar panel and $L C$ component of SZSI network reduces.

\section{References}

[1] Peng F. Z. 2003. Z-source inverter. IEEE Trans. on Industry Application. 39: 504-510.

[2] Shen M and Peng F. Z. 2008. Operation Modes and Characteristics of the Z-Source Inverter with Small Inductance or Low Power Factor. IEEE Trans. on Industrial Electronics. 55: 89-96.

[3] F. Z. Peng, Yuan X., Fang X., and. Qian Z. 2003. Z-source inverter for adjustable speed drives. IEEE Power Electronics Letter. 1:33-35.

[4] Renge M., Suryawanshi H and Chaudhari M. 2010. Digital Implemented Noval Technique to Approach Natural Sampling SPWM. EPE Journal. 20:13-20.

[5] Huang Yi, Shen Miaosen, Peng F. Z and Wang Jin. 2006. Z-Source inverter for residential photovoltaic Systems. IEEE Trans. on Power Electronics.21:2006.

[6] Tang Yu, Xie Shaojun and Ding Jiudong. 2014. Pulsewidth Modulation of Z- Source Inverters With Minimum Inductor Current Ripple. IEEE Trans. on Industrial Electronics.61: 98-106.

[7] Adle R.V., Renge M and Muley S.P. 2015. Series Z-Source Inverter Fed Motor Drive. Industrial Instrumentation and Control (ICIC) 2015 International Conference. 956-959.

[8] Adle R.V., Renge M and Muley S.P. 2016. Improved Performance of Series Z-Source Inverter For Motor Drive. 2016 IEEE Students' Conference on Electrical, Electronics and Computer Science (SCEECS).1-4. 